\section{P2-276 INFLUENCE OF SMOKING AND SMOKING CESSATION ON PULMONARY FUNCTION IN JAPANESE HEALTHY PEOPLE}

doi:10.1136/jech.2011.142976k.9

${ }^{1} \mathrm{M}$ Shigeta, ${ }^{* 1} \mathrm{E}$ Ozaki, ${ }^{1} \mathrm{~N}$ Kuriyama, ${ }^{1} \mathrm{D}$ Matsui, ${ }^{1} \mathrm{I}$ Watanabe, ${ }^{1} \mathrm{~K}$ Inoue, ${ }^{1} \mathrm{~A}$ Nakazawa, ${ }^{1,2} \mathrm{~K}$ Ozasa, ${ }^{1} \mathrm{Y}$ Watanabe. ${ }^{1}$ Kyoto Prefectural University of Medicine, Kyoto, Japan; ${ }^{2}$ Radiation Effects Research Foundation, Hiroshima, Japan

Background and Objective Chronic obstructive pulmonary disease has been increasing throughout the world. Many studies show that smoking accelerate decline in pulmonary function and smoking cessation can improve it, but there are very few studies focusing effect of smoking cessation in Japanese people. Therefore we investigated influence of smoking/smoking cessation on pulmonary function.

Subjects and Method Subjects were 3913 (55.7 \pm 10.5 years old) male who underwent medical check-up in a hospital during 2004. We compared pulmonary functions with stratified analysis among 1096 current smokers (CS), 1706 ex-smokers (ES) and 1111 never smokers (NS) using ANOVA.

Result There were significant differences respectively among the three groups, in the following order of NS, ES, CS: FEV 1.0 (Forced Expiratory Volume in 1 second) \%: $82.8 \pm 5.9,80.5 \pm 6.8,79.8 \pm 7.2, \%$ $\mathrm{FEV}_{1.0}$, Peak Flow, $\mathrm{V}_{75}, \% \mathrm{~V}_{50}$ and $\% \mathrm{~V}_{25}$. In their 40 s, 50 s and 60 s, ES preserved better pulmonary function than CS consistently and the subjects who quit younger showed the more favourable function. Conclusion Smoking impaired pulmonary function obviously and smoking cessation improved pulmonary function in Japanese people as Western. However earlier cessation was related to larger improvement, even 60s-quitter had certain effect.

\section{P2-277 ALCOHOL DRINKING AND PRIMARY LIVER CANCER IN JAPANESE: A POOLED ANALYSIS OF FOUR COHORT STUDIES}

doi:10.1136/jech.2011.142976k.10

\begin{abstract}
${ }^{1} \mathrm{~T}$ Shimazu, ${ }^{*}$ S Sasazuki, ${ }^{2} \mathrm{~K}$ Wakai, ${ }^{3} \mathrm{~A}$ Tamakoshi, ${ }^{4} \mathrm{I}$ Tsuji, ${ }^{4} \mathrm{Y}$ Sugawara, ${ }^{5} \mathrm{~K}$ Matsuo, ${ }^{6} \mathrm{C}$ Nagata, ${ }^{7} \mathrm{~T}$ Mizoue, ${ }^{8} \mathrm{~K}$ Tanaka, ${ }^{1} \mathrm{M}$ Inoue, ${ }^{1} \mathrm{~S}$ Tsugane. ${ }^{1}$ National Cancer Center, Tokyo, Japan; ${ }^{2}$ Nagoya University Graduate School of Medicine, Nagoya, Japan; ${ }^{3}$ Aichi Medical University School of Medicine, Aichi, Japan; ${ }^{4}$ Tohoku University Graduate School of Medicine, Sendai, Japan; ${ }^{5}$ Aichi Cancer Center Research Institute, Nagoya, Japan; ${ }^{6}$ Gifu University Graduate School of Medicine, Gifu, Japan; ${ }^{7}$ National Center for Global Health and Medicine, Tokyo, Japan; ${ }^{8}$ Saga University, Saga, Japan
\end{abstract}

Introduction Because studies of the association between alcohol intake and the risk of primary liver cancer use varying cut-off points to classify alcohol intake, it is difficult to precisely quantify this association by meta-analysis of published data. Furthermore, there are limited data for women in prospective studies of the dosespecific relation of alcohol intake and the risk of primary liver cancer. Methods We analysed original data from four population-based prospective cohort studies encompassing 174719 participants (8986 men and 84856 women). After adjustment for a common set of variables, we used Cox proportional hazards regression to estimate HRs and $95 \%$ CIs of primary liver cancer incidence according to alcohol intake. We conducted a meta-analysis of the HRs derived from each study.

Results During 1964136 person-years of follow-up, 804 primary liver cancer cases (605 men and 199 women) were identified. In male drinkers, the multivariate-adjusted HRs $(95 \% \mathrm{CI})$ for alcohol intakes of $0.1-22.9,23.0-45.9,46.0-68.9,69.0-91.9$, and $\geq 92.0 \mathrm{~g} /$ day, as compared with occasional drinkers, were 0.88 (0.57 to 1.36 ), 1.06 (0.70 to 1.62$), 1.07$ (0.69 to 1.66$), 1.76$ (1.08 to 2.87 ), and 1.66 (0.98 to 2.82 ), respectively ( $p$ for trend $=0.015$ ). In women, we observed a significantly increased risk among those who drank $\geq 23.0 \mathrm{~g} /$ day, as compared with occasional drinkers (HR: 3.60; 95\% CI 1.22 to 10.66). Conclusion This pooled analysis of data from large prospective studies in Japan indicates that avoidance of (1) heavy alcohol drinking ( $\geq 69.0 \mathrm{~g}$ alcohol/day) in men and (2) moderate drinking $(\geq 23.0 \mathrm{~g}$ alcohol/day) in women may reduce the risk of primary liver cancer

\section{P2-278 ALTRUISTIC MOTIVATION FOR PRO-SOCIAL BEHAVIOUR PREDICT DECREASED RISK OF CARDIOVASCULAR MORTALITY AMONG COMMUNITY DWELLING POPULATION IN JAPAN: JACC STUDY}

doi:10.1136/jech.2011.142976k.11

${ }^{1,2} \mathrm{~K}$ Shirai, ${ }^{*} \mathrm{H}$ Iso, ${ }^{3} \mathrm{H}$ Noda, ${ }^{3} \mathrm{~T}$ Ohira, ${ }^{4} \mathrm{~K}$ Tanno, ${ }^{4} \mathrm{~K}$ Sakata, ${ }^{5} \mathrm{~A}$ Tamakoshi. ${ }^{1}$ Harvard School of Public Health, Boston, Massachusetts, USA; ${ }^{2}$ University of the Ryukyus, Nishihara, Okinawa, Japan; ${ }^{3}$ Osaka University, Suita, Osaka, Japan; ${ }^{4}$ wwate Medical University, Morioka, Iwate, Japan; ${ }^{5}$ Aichi Medical University, Nagoya, Aichi, Japan

Objectives This study examine the effects of sense of being relied by others reflecting altruistic motivation for pro-social behaviour on cardiovascular disease mortality among Japanese community residents.

Method Subjects were 99969 Japanese men and women aged 40-79 years free from cardiovascular and cancer disease at baseline 1988-1990, included in the Japan Collaborative Cohort Study. Sexspecific age and multivariable adjusted HRs were calculated according to the perceived level of being relied by others from Cox proportional hazard models to estimate the risks of cardiovascular mortality. Additionally, one-to-one nearest neighbour propensity score matching analysis were carried using a probit model

Result Among 41906 men and 58063 women followed up for 14.4 years in median, a total of 4280 (2320 men and 1960 women) cardiovascular deaths were documented. The multivariable HRs of total cardiovascular disease deaths for men with the highest sense of being relied by others to compare with those in the lowest were 0.65 (95\% CI 0.52 to 0.82$)$, $p$ for trend $p=0.03$ for stroke, and 0.75 ( $95 \%$ CI 0.64 to 0.88 ), $\mathrm{p}$ for trend $=0.004$, for total cardiovascular deaths with dose responses. For both men and women, they were not associated with coronary heart disease deaths. The HRs and the $95 \% \mathrm{CIs}$ calculated in the matching technique were not grossly different.

Conclusion A lower level of sense of being relied by others was found to be associated with higher risk of cardiovascular disease mortality among middle-aged men, suggesting a protective role of altruistic psychological conditions on cardiovascular disease.

\section{P2-279 10-YEAR MORTALITY FOLLOW-UP OF MATERNAL AND PATERNAL GRANDPARENTS SHOWS DIFFERENT PATTERNS OF ASSOCIATION WITH THEIR GRANDCHILDREN'S BIRTH WEIGHTS: THE LIFEWAYS CROSS GENERATION COHORT STUDY}

doi:10.1136/jech.2011.142976k.12

A Shrivastava, ${ }^{*}$ C Murrin, C Kelleher, for the Lifeways Cross Generation Cohort Study Steering Group.

Health Research Board Centre for Diet and Health Research, School of Public Health, Physiotherapy and Population Science, University College Dublin, Dublin 4, Ireland

Introduction Association between individual birth measures and chronic disease morbidity or mortality in their adult relatives contributes to evidence of developmental origins of disease. 